\title{
The management of spontaneous pneumothorax
}

\author{
C. V. RUCKLEY AND R. J. M. M CCORMACK \\ From the Thoracic Surgical Unit, Royal Infirmary, Edinburgh
}

In $1932 \mathrm{Kjaergaard}$ corrected the universally held belief that spontaneous pneumothorax was usually a manifestation of active tuberculosis. To-day the pathology of the condition is well understood but there is no general agreement about therapy. In the literature, the treatment varies from the extremely conservative, with bed-rest alone in most cases (Vail, Alway, and England, 1960; Hyde, 1963), to early thoracotomy (MacQuigg, 1955; Watkins and Hering, 1961) or even bilateral thoracotomy (Baronofsky, Warden, Kaufman, Whatley, and Hanner, 1957). It is the purpose of this paper, by reviewing 242 patients, to assess the efficacy of surgical management as practised in Edinburgh.

\section{MATERIAL}

In the 10-year period 1953-63, 242 cases of spontaneous pneumothorax were treated in the Thoracic Surgical Unit in Edinburgh. Although composed of consecutive cases, this is a selected series in so far as the patients were referred to a surgical unit. A large number were transferred from other wards. In comparison with most other series there is a relatively higher proportion of three groups of patients - the 'very ill', the 'failed conservative treatment', and the 'recurrent pneumothorax'.

AGE, SEX, AND SIDE Figure 1 shows that the highest incidence in this series is in the third decade. A second peak occurs in the sixth decade. There is a contrast between the age incidence in our series and that in published American series, of which a typical recent example, selected only because it is of similar size, is shown for comparison (Hyde, 1963). There were 210 men and 32 women. The right side was affected in $130(53.7 \%)$ and the left in $106(43.8 \%)$, and in six $(2.5 \%)$ there were simultaneous bilateral pneumothoraces.

CLINICAL FEATURES Neither occupation nor physical exertion could be related to the onset of spontaneous pneumothorax. Pain, dyspnoea, and cough marked the onset in most patients. Some

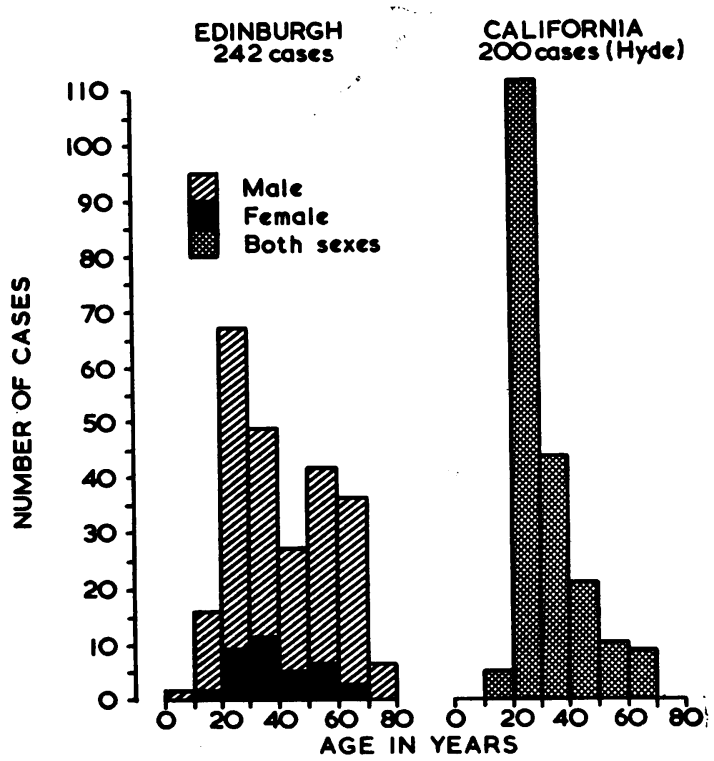

FIG. 1. Incidence of spontaneous pneumothorax.

TABLE I

SPONTANEOUS PNEUMOTHORAX: ATYPICAL PRESENTATION

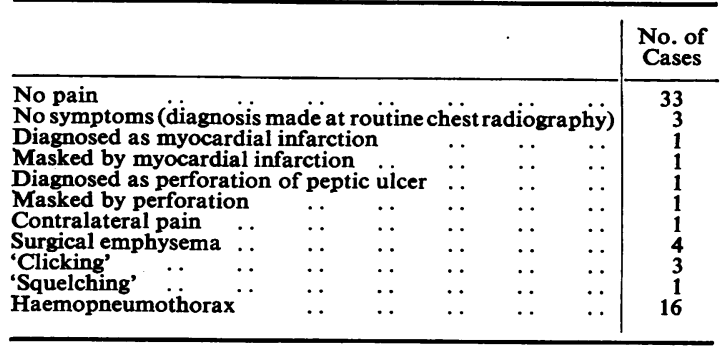

of the more unusual ways in which attacks presented are shown in Table $I$.

Associated chest disease Table II shows the age incidence of associated chest disease. One hundred and twenty-three patients $(50.8 \%)$ had had past or present disease. Sixty-three had chronic bronchitis and emphysema, or pneumoconiosis; 
T A B LE II

SPONTANEOUS PNEUMOTHORAX AND ASSOCIATED CHEST DISEASE (123 PATIENTS)

\begin{tabular}{|c|c|c|c|c|c|c|c|c|}
\hline \multirow{2}{*}{ Age } & \multirow{2}{*}{ Asthma } & \multicolumn{2}{|c|}{ Tuberculosis } & \multicolumn{2}{|c|}{ Pneumonia } & \multirow{2}{*}{$\begin{array}{c}\text { Car- } \\
\text { cinoma }\end{array}$} & \multirow{2}{*}{$\begin{array}{l}\text { Chronic } \\
\text { Bron- } \\
\text { chitis }\end{array}$} & \multirow{2}{*}{ Total } \\
\hline & & $\begin{array}{l}\text { Cur- } \\
\text { rent }\end{array}$ & Past & $\begin{array}{l}\text { Cur- } \\
\text { rent }\end{array}$ & Past & & & \\
\hline $\begin{array}{r}0-39 \\
40-79 \\
\end{array}$ & $\begin{array}{l}8 \\
1\end{array}$ & $\begin{array}{l}5 \\
2 \\
\end{array}$ & $\begin{array}{r}7 \\
14\end{array}$ & $\begin{array}{l}2 \\
7\end{array}$ & $\begin{array}{l}13 \\
15 \\
\end{array}$ & $\begin{array}{l}0 \\
5 \\
\end{array}$ & $\begin{array}{r}2 \\
61 \\
\end{array}$ & $\begin{array}{r}37 \\
105 \\
\end{array}$ \\
\hline$\overline{\text { Total }}$ & 9 & 7 & 21 & 9 & 28 & 5 & 63 & $\overline{142}$ \\
\hline
\end{tabular}

28 had had pneumonia or pleurisy; 21 had had pulmonary tuberculosis; nine had asthma; and one had pulmonary eosinophilia with honeycomb lung. At the time of admission nine patients had acute respiratory infections with purulent sputum and pyrexia, seven had active pulmonary tuberculosis, five had bronchial carcinoma, one had a bronchial adenoma, and one had suffered a recent myocardial infarction. No attempt has been made to separate these latter patients from those in whom no definite pathology was demonstrated, because 'spontaneous' pneumothorax must always be secondary to a pulmonary or pleural abnormality, whether it is congenital or acute or chronic acquired disease.

If we extract the 63 cases of chronic bronchitis and emphysema and pneumoconiosis and show them in relation to age incidence, the importance of these diseases in the older age-group becomes apparent (Fig. 2). Since this is a retrospective study and these conditions were not specifically looked for, it is almost certain that the true inci-

Chronic bronchitis Other chest diseases

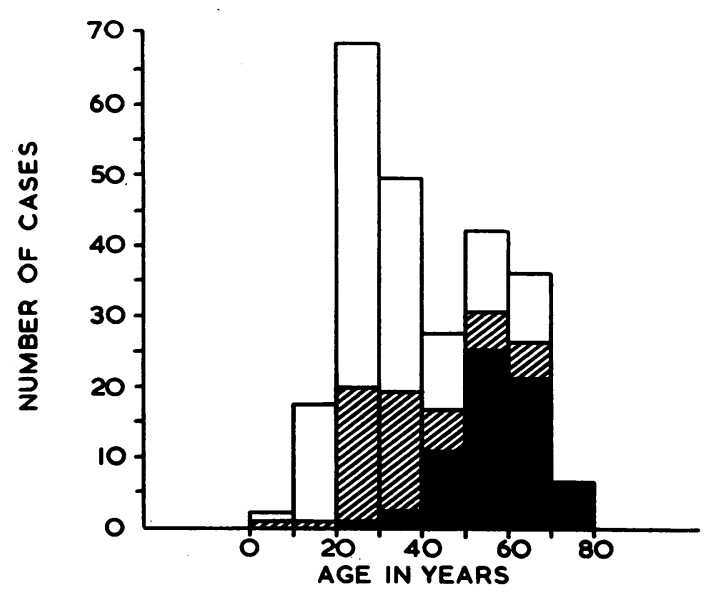

FIG. 2. Age and pulmonary disease. dence was higher. It seems probable that the difference between the age incidence in this series and in American series lies in the frequency of chronic bronchitis in this country.

Bilateral pneumothoraces Twenty-four patients $(10 \%)$ had bilateral pneumothoraces, of which six $\vec{\circ}$ occurred simultaneously.

Recurrent pneumothoraces Seventy-three patients $(32 \%)$ had had previous attacks on the same side. Table III shows the number of previous attacks experienced and also how they had been treated.

\section{T A B L E I I I}

PREVIOUS IPSILATERAL ATTACKS OF SPONTANEOUS PNEUMOTHORAX

\begin{tabular}{|c|c|c|c|c|c|c|}
\hline \multirow{2}{*}{$\begin{array}{l}\text { Previous Method of } \\
\text { Treatment }\end{array}$} & \multicolumn{5}{|c|}{ Number of Previous Attacks } & \multirow[b]{2}{*}{ Total } \\
\hline & 1 & 2 & 3 & 4 & $\begin{array}{l}5 \text { or } \\
\text { More }\end{array}$ & \\
\hline $\begin{array}{l}\text { Bed rest } \\
\text { Needle aspiration } \\
\text { Tube.. }\end{array}$ & $\begin{array}{r}19 \\
4 \\
5\end{array}$ & $\begin{array}{r}14 \\
1 \\
5\end{array}$ & $\begin{array}{l}6 \\
2 \\
5\end{array}$ & $\underline{5}$ & $\frac{6}{1}$ & $\begin{array}{r}50 \\
7 \\
16\end{array}$ \\
\hline Total. . & 28 & 20 & 13 & 5 & 7 & 73 \\
\hline
\end{tabular}

The majority had had at least two previous attacks and nearly one-third had had three or more. One patient had had 15 and another 12. Eighty per cent. had been treated by bed-rest alone or by bed-rest plus needle aspiration of air. Twenty per cent. had been treated by pleural catheterization during at least one of the previous attacks. Seven of the recurrent cases were classed as emergency admissions.

URGENT ADMISSIONS Forty-eight patients were classed as emergency admissions on the basis of severe dyspnoea and cyanosis, shock, or unconsciousness. Seventeen were in severe respiratory failure on admission, three being comatose, and in this group one had a bronchial carcinoma, two had active tuberculosis, and all the others had chronic bronchitis. Eight of these 17 patients required tracheostomy and assisted respiration. Four patients had marked surgical emphysema. Nine out of the 16 patients with haemopneumothorax were seriously ill and required transfusion. There were four hospital deaths in the whole series, and all occurred among the emergency admissions. The respective necropsy findings were bronchopneumonia, cor pulmonale, myocardial infarction, and bronchial carcinoma. No residual pneumothorax was found in any case at necropsy. 
TREATMENT The principles of treatment throughout this period were (1) at the earliest convenient time a Malecot catheter was inserted into the pneumothorax, usually through the second intercostal space anteriorly; (2) suction was applied unless there was evidence of a persisting sizable fistula ; and (3) the tube was removed on about the fifth day, provided that the radiograph showed satisfactory pulmonary re-expansion and that the respiratory variation in intrapleural pressure was no longer transmitted to the water-seal.

In $50 \%$ of cases it was necessary to insert one or more further tubes to attain full pulmonary re-expansion. The management of the patients in this series is summarized in Table IV. In 11 patients with a very small pneumothorax, five

TABLE IV

TREATMENT OF SPONTANEOUS PNEUMOTHORAX

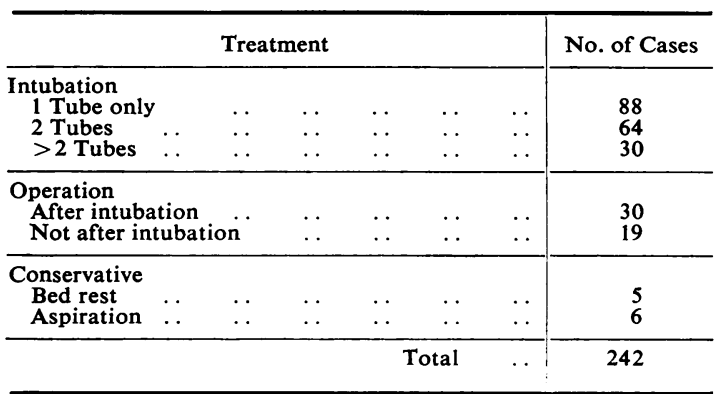

were simply observed and, early in the series, pleurodesing agents were used in six. One hundred and eighty-two patients were treated by intubation alone. Thirty, after initial intubation, were treated by thoracotomy, and 19 underwent thoracotomy without previous intubation, giving a total of 49 operated cases.

A summary of the indications for operation (Table V) shows that recurrence and persisting air leak comprise the majority. Table VI shows that the standard procedure of pleurectomy was carried out in 35 patients. It was combined with

TABLE V

INDICATIONS FOR OPEN THORACOTOMY IN 49 CASES

\begin{tabular}{|c|c|c|c|}
\hline \multicolumn{3}{|c|}{ Indication } & No. \\
\hline $\begin{array}{l}\text { Recurrence } \\
\text { Persistence } \\
\text { Haemothorax } \\
\text { Pyopneumothorax } \\
\text { Adenoma... } \\
\text { Large cysts } \\
\text { Previous contralat }\end{array}$ & $\begin{array}{l}\cdots \\
\cdots \\
\cdots \\
\cdots \\
\ldots \\
\text { attack }\end{array}$ & $\begin{array}{l}\cdots \\
\cdots \\
\cdots \\
\cdots \\
\cdots\end{array}$ & $\begin{array}{r}21 \\
27 \\
5 \\
2 \\
1 \\
2 \\
1\end{array}$ \\
\hline
\end{tabular}

TABLE VI

SUMMARY OF OPERATIVE PROCEDURES IN 49 CASES

\begin{tabular}{llll|r}
\hline \multicolumn{3}{c|}{ Operation } & & No. \\
\hline Pleurectomy & $\ldots$ & $\ldots$ & $\ldots$ & 35 \\
Decortication & $\ldots$ & $\ldots$ & $\ldots$ & 28 \\
Bullae oversewn & $\ldots$ & $\ldots$ & 21 \\
Bullae excised & $\ldots$ & $\ldots$ & $\ldots$ & 6 \\
Segmental resection & $\ldots$ & $\ldots$ & 2 \\
Lobectomy $\ldots$ & $\ldots$ & $\ldots$ & 1 \\
Excision of adenoma & $\ldots$ & $\ldots$ & 1 \\
\hline
\end{tabular}

oversewing of bullae in 21 , excision and oversewing in six, segmental resection in two, and lobectomy in one. Decortication was necessary in eight patients.

The operation of pleurectomy, as practised in this unit, consists of the stripping of the parietal pleura from the chest wall and from the upper mediastinum. The pleura covering the remainder of the mediastinum and the surface of the diaphragm is left intact (le Roux, 1964).

DURATION OF HOSPITAL STAY Sixty-one per cent. of all patients spent less than two weeks in hospital. Management without active treatment was reserved for those patients with very small pneumothoraces, and all except two in this group were discharged in less than one week. One hundred and sixteen $(65.3 \%)$ of the patients treated by intubation were discharged in less than two weeks and, of those treated by operation, 32 $(65.2 \%)$ spent less than three weeks in hospital. The longest hospital stay was four months. This was the patient described elsewhere who developed empyema which required decortication.

FOLLOW-UP Contact has been established with 218 patients, and a further six were followed for periods of one to four years before contact was lost, giving a one- to eleven-year follow-up of 224 patients $(93 \%)$ (Table VII). The majority of patients either were seen personally or replied to a questionnaire, but in a few cases the information was supplied by the general practitioner.

After discharge from the Thoracic Unit 28 patients $(12.5 \%)$ developed a recurrence of pneumothorax (Table VIII). Twenty-six had been treated by intubation, and two had had no active treatment. Sixteen were once again treated by intubation, five by thoracotomy, and in the remaining seven the recurrent pneumothoraces were so small that no active treatment was required. It is worth noting that in only one patient was the recurrence found to be larger than its predecessor. In the other instances adhesions limited the extent of the pneumothorax. 
TABLE VII

FOLLOW-UP OF PATIENTS WTTH SPONTANEOUS PNEUMOTHORAX

\begin{tabular}{c|c|c}
$\begin{array}{c}\text { Duration of } \\
\text { Follow-up (yrs.) }\end{array}$ & $\begin{array}{c}\text { No. of } \\
\text { Patients }\end{array}$ & Deaths \\
\hline 6 months to 1 & 10 & 12 \\
$1-2$ & 26 & \\
$2-3$ & 38 & 1 \\
$3-4$ & 35 & \\
$4-5$ & 22 & \\
$5-6$ & 21 & \\
$6-7$ & 14 & \\
$7-8$ & 11 & \\
$8-9$ & 16 & \\
$9-10$ & 6 & \\
$10-11$ & 12 & \\
\hline Total & & \\
\hline
\end{tabular}

TABLE VIII

RECURRENCE OF SPONTANEOUS PNEUMOTHORAX

\begin{tabular}{ll|c|c}
\multicolumn{1}{c|}{$\begin{array}{c}\text { Mode of } \\
\text { Treatment }\end{array}$} & $\begin{array}{c}\text { No. of Cases } \\
\text { Followed Up }\end{array}$ & $\begin{array}{c}\text { No. of } \\
\text { Recurrences }\end{array}$ \\
\hline $\begin{array}{l}\text { Conservative } \\
\text { Intubation } \\
\text { Thoracotomy }\end{array}$ & $\ldots$ & 7 & $2(18 \cdot 1 \%)$ \\
\hline Total & $\ldots$ & 168 & $26(14 \cdot 8 \%)$ \\
0 & 49 & $28(12 \cdot 5 \%)$
\end{tabular}

Table IX shows that $50 \%$ of recurrences occurred within six months of discharge, and only one occurred more than three years later. Similar observations have been made in other series (Crowther, 1955). For two patients information as to the date of recurrence was lacking. Twenty patients have died during the period of follow-up.

TABLE IX

TIME INTERVAL OF RECURRENCE AFTER TREATMENT

\begin{tabular}{ccccc|c}
\multicolumn{3}{c|}{$\begin{array}{c}\text { After Discharge from } \\
\text { Thoracic Unit (mths) }\end{array}$} & $\begin{array}{c}\text { No. of } \\
\text { Cases }\end{array}$ \\
\hline$<1$ & $\ldots$ & $\ldots$ & $\ldots$ & $\ldots$ & 6 \\
$1-2$ & $\ldots$ & $\ldots$ & $\ldots$ & $\ldots$ & 5 \\
$3-6$ & $\ldots$ & $\ldots$ & $\ldots$ & $\ldots$ & 4 \\
$7-12$ & $\ldots$ & $\ldots$ & $\ldots$ & $\ldots$ & 2 \\
$13-36$ & $\ldots$ & $\ldots$ & $\ldots$ & $\ldots$ & 8 \\
$>36$ &. & $\ldots$ & $\ldots$ & 1 \\
Information not available & $\ldots$ & 2
\end{tabular}

None is known to have had a pneumothorax at the time of death, but in half of them it was not possible to obtain necropsy data.

COMPLICATIONS Complications of surgical treatment were rare (Table $\mathrm{X}$ ). The only patient who developed empyema after intubation had a severe respiratory infection on admission. The empyema was treated by open drainage followed by thoracoplasty, and the patient is well five years later. A complication followed thoracotomy in four patients. A bronchopleural fistula progressed to empyema in one and decortication was
TABLE $X$ COMPLICATIONS

\begin{tabular}{lll|c} 
& & No. \\
\hline $\begin{array}{c}\text { After intubation } \\
\text { Empyema .. }\end{array}$ & $\ldots$ & $\ldots$ & 1 \\
\hline $\begin{array}{c}\text { After operation } \\
\text { Empyema . . }\end{array}$ & $\ldots$ & $\ldots$ & 1 \\
Haemothorax & $\ldots$ & $\ldots$ & 1 \\
Osteitis . & $\ldots$ & $\ldots$ & 1 \\
Encephalitis & $\ldots$ & $\ldots$ & 1 \\
Death . & $\ldots$ & $\ldots$ & 0
\end{tabular}

required. Pleurectomy was followed in one by haemothorax which was evacuated by aspiration. A third developed osteitis of a rib, and this was resected. The fourth developed encephalitis postoperatively. He made a full recovery. There were no operative deaths.

\section{DISCUSSION}

We submit that the management of spontaneous pneumothorax demands an appreciation of two factors - the potential dangers of the condition and the financial hardships involved if rapid reexpansion is not obtained or if the pneumothorax is recurrent.

The three important hazards to which the patient with spontaneous pneumothorax is exposed are tension pneumothorax, associated haemothorax, and respiratory failure. A positive pressure may develop at any time in the pneumothorax, and the onset of tension may be sudden and dramatic. The association of intrapleural haemorrhage with pneumothorax adds greatly to the risk, and Gaensler (1956) found a reported mortality in this lesion of $26 \%$. Respiratory failure does not occur in the previously healthy patient who develops a pneumothorax, but when respiratory reserves are already impaired by established lung disease, usually chronic bronchitis, the occurrence of even a small pneumothorax may be all that is required to precipitate respiratory failure.

Apart from these dangers to life, the economic aspect is important. A collapsed lung, when treated by bed-rest alone, is slow to re-expand even when the fistula has sealed immediately. The average rate of absorption of air from the pleural space, as calculated by radiographic lung volume studies, is $1.25 \%$ per day (Kircher and Swartzel, 1954). For example, a $45 \%$ pneumothorax will take 36 days to reabsorb. Pneumothoraces of more than $50 \%$ constitute some two-thirds of any reviewed series, and therefore in this proportion spontaneous re-expansion would take some six 
weeks and considerably longer if an air leak persists. Sixty-one per cent. of patients in this series were discharged in less than two weeks. Published accounts confirm the delay that inactivity incurs. Hyde (1963) treated 171 patients by observation only. The average expansion time was four weeks. In the series of 115 patients reported by Myers (1954), 89 (78\%) pneumothoraces took between three weeks and three months to re-expand: one patient early in his series was treated by bed-rest for one year. One patient in our series was observed for four months before being referred for surgical treatment. The combination of loss of earnings and the cost of hospital bed occupancy makes quite clear the economic importance of active treatment in such cases.

A patient with a total pulmonary collapse treated by catheterization is usually back at work in one week. An alternative method of accelerating pulmonary re-expansion is the needle aspiration of air, sometimes carried out repeatedly. Except as an emergency procedure for the relief of tension, this method is to be condemned. Needle aspiration, with the possibility of lacerating the lung, may open the way to complications such as empyema and chronic pneumothorax. Pleural intubation, provided that it is done with sterile precautions-and in this series it was done under theatre conditions-allows rapid pulmonary re-expansion with minimal danger of infective sequelae. In this series recurrent pneumothoraces tended to be smaller than in the original attack, and a further point in favour of catheterization may be that the presence of the tube promotes pleural adhesions and may increase the margin of safety if there should be a recurrence.

There remains the question of prevention of recurrence. A survey of the literature suggests that most authors have experienced difficulty in obtaining reliable figures for recurrences in their series. Gaensler (1956), in reviewing 1,080 cases in the literature, found an average recurrence rate of $22.7 \%$. Lindskog and Halasz (1957), with an $87.5 \%$ follow-up of 72 patients treated conservatively, found $18 \%$ recurrence. Myers (1954) obtained a $90.5 \%$ follow-up of 115 patients treated conservatively and found $24 \%$ recurrence. After intubation Reid, Stevenson, and McSwan (1963) found an $11 \%$ recurrence rate in 46 patients, but the percentage follow-up is not given. Wolcott, Shaver, and Jennings (1963), with a $75 \%$ follow-up of 65 patients, found $17 \%$ recurrence after intubation. In this series a $90.2 \%$ follow-up of 182 patients treated by intubation shows a $14.8 \%$ recurrence rate. This compares favourably with other series (Table XI). There was no recurrence after thoracotomy. The overall recurrence rate was therefore $12.5 \%$.

Pleurodesing agents have seldom been used in this series. Brock (1948) has treated recurrent

TABLE XI

RECURRENCE RATES

\begin{tabular}{|c|c|c|c|c|}
\hline Series & $\begin{array}{l}\text { No. of } \\
\text { Cases }\end{array}$ & $\begin{array}{l}\text { Follow } \\
\text { Up }(\%)\end{array}$ & Treatment & $\begin{array}{l}\text { Recurrence } \\
\text { Rate }(\%)\end{array}$ \\
\hline Gaensler (1956) . . & 1,080 & $?$ & Various & $22 \cdot 7$ \\
\hline $\begin{array}{ll}\text { (1959) } & \ldots \\
\text { Myers (1954) } & \ldots \\
\text { Rottenberg and } & \end{array}$ & $\begin{array}{r}72 \\
115\end{array}$ & $\begin{array}{l}87.5 \\
90.5\end{array}$ & $\begin{array}{l}\text { Conservative } \\
\text { Conservative }\end{array}$ & $\begin{array}{l}18 \\
24\end{array}$ \\
\hline $\begin{array}{l}\text { Golden }(1949) \\
\text { Reid et al. }(1963) \\
\text { Wolcott et al. }(1963) \\
\text { This series } \ldots\end{array}$ & $\begin{array}{r}105 \\
46 \\
65 \\
182\end{array}$ & $\begin{array}{l}? \\
? \\
7 \dot{5} \\
90 \cdot 2\end{array}$ & $\begin{array}{l}\text { Conservative } \\
\text { Tube } \\
\text { Tube } \\
\text { Tube }\end{array}$ & $\begin{array}{l}20 \cdot 8 \\
11 \\
17 \\
14 \cdot 8\end{array}$ \\
\hline
\end{tabular}

pneumothoraces successfully by spraying the visceral pleura with silver nitrate. Others report less favourable results (Gaensler, 1956 ; Frankel, Krasna, and Baronofsky, 1961). It has been the experience in this unit that the pain and systemic disturbance provoked by this procedure is scarcely less than that of thoracotomy. There may be a place for instilling a small quantity of the patient's own blood. When a pleurodesing agent is used, it should be combined with catheterization to ensure pleural apposition. Many authors advocate the application of these agents at thoracotomy (Driscoll and Aronstam, 1961 ; Shefts, Gilpatrick, Swindell, and Gabbard, 1954). We have found pleurectomy to be a quick, safe, and effective alternative. We have had no recurrence of pneumothorax after resection of the parietal pleura, and this is also the experience of Saha (1964). It may be argued that the mechanical efficiency of respiration is disturbed by pleurectomy. Gaensler (1956) and Andersen and Poulsen (1959) have demonstrated by detailed function tests that there is no significant impairment. The finding is borne out by post-operative respiratory function tests on patients in this series.

On the basis of this study we suggest the following policy as the best for the management of spontaneous pneumothorax. In all patients, with or without associated lung disease, the first attack should be treated with intubation, unless the pneumothorax is very small, when no treatment is necessary. When the pneumothorax recurs in the otherwise healthy patient, pleurectomy is carried out and bullae are oversewn: this procedure is also adopted in the initial attack if there is a persisting air leak or if there is radiological evidence of large bullae. Recurrent pneumothoraces in the older patient with associated 
chronic bronchitis and emphysema may also be treated by pleurectomy, but if the pulmonary function is very poor, repeated intubation is the safer course. Bronchoscopy with aspiration of secretions is indicated if there is radiological evidence of absorption collapse. Thoracoscopy adds little of value to the management. Caustic pleural irritants are avoided. This scheme of management is similar to that followed by Carr, Silver, and Ellis (1963), who obtained similarly satisfactory results.

\section{SUMMARY}

This paper describes 242 consecutive cases of spontaneous pneumothorax treated in a thoracic surgical unit. One hundred and eighty-four patients were treated by pleural catheterization and 49 by thoracotomy; 11 with very small pneumothoraces were treated conservatively. The overall recurrence rate, shown by a $92 \%$ followup, was $12.5 \%$. There was no recurrence after thoracotomy. The recurrence rate after intubation was $14.3 \%$.

The advantages of the active surgical management of spontaneous pneumothorax are outlined.

\section{REFERENCES}

Andersen, I., and Poulsen, T. (1959). Surgical treatment of spontaneous pneumothorax. Acta chir. scand., 118, 105.

Baronofsky, I. D., Warden, H. G., Kaufman, J. L., Whatley, J., and Hanner, J. M. (1957). Bilateral therapy for unilateral spontaneous pneumothorax. J. thorac. Surg., 34, 310.
Brock, R. C. (1948). Recurrent and chronic spontaneous pneumothorax. Thorax, 3,88.

Carr, D. T., Silver, A. W., and Ellis, F. H., Jr. (1963). Management of spontaneous pneumothorax: with special reference to prognosis after various kinds of therapy. Proc. Mayo Clin., 38, 103 .

Crowther, J. S. (1955). Spontaneous pneumothorax; a review of 61 cases. Tubercle (Lond.), 36, 265.

Driscoll, P. J., and Aronstam, E. M. (1961). Experiences in the management of recurrent spontaneous pneumothorax. J. thorac cardiovasc. Surg., 42, 174.

Frankel, A., Krasna, I., and Baronofsky, I. D. (1961). An experimental study of pleural symphysis. Ibid., 42, 43.

Gaensler, E. A.(1956). Parietal pleur ectomy for recurrent spontaneous pneumothorax. Surg. Gynec. Obstet., 102, 293.

Hyde, L. (1963). Spontaneous pneumothorax. Dis. Chest, 43, 476.

Kircher, L. T., Jr., and Swartzel, R. L. (1954). Spontaneous pneumothorax and its treatment. J. Amer. med. Ass., 155, 24.

Kjaergaard, H. (1932). Spontaneous pneumothorax in the apparently healthy. Acta med. scand., suppl., 43, 1.

le Roux, B. T. (1964). The place of pleurectomy in the management of spontaneous pneumothorax. J. roy. Coll. Surg. Edinb., 9, 218.

Lindskog, G. E., and Halasz, N. A. (1957). Spontaneous pneumothorax; a consideration of pathogenesis and management with review of 72 hospitalized cases. Arch. Surg., 75, 693.

MacQuigg, R. E. (1955). Spontaneous pneumothorax: the case for early thoracotomy. Amer. Surg., 21, 478.

Myers, J. A. (1954). Simple spontaneous pneumothorax. Dis. Chest, 26,420 .

Reid, J. M., Stevenson, J. G., and McSwan, N. (1963). The management of spontaneous pneumothorax. Scot. med. J., 8, 171.

Rottenberg, L. A., and Golden, R. (1949). Spontaneous pneumothorax, Survey of 105 cases. Radiology, 53, 157.

Saha, D. (1964). Parietal pleurectomy for prevention of recurrent spontaneous pneumothorax. Brit.J. Dis. Chest, 58, 78.

Shefts, L. M., Gilpatrick, C., Swindell, H., and Gabbard, J. G.(1954). Management of spontaneous pneumothorax. Dis. Chest, 26, 273.

Vail, W. J., Alway, A. E., and England, N. J. (1960). Spontaneous pneumothorax. Ibid. 38, 512.

Watkins, E., Jr., and Hering, A. C. (1961). Indications for surgical intervention in "spontaneous" pneumothorax. Surg. Clin. $N$. Amer., 41, 709.

Wolcott, M. W., Shaver, W. A., and Jennings, W. D. (1963). Spontaneous pneumothorax. Management by tube thoracostomy and suction. Dis. Chest, 43,78 . 